\title{
Erratum to: Dusting Off the Messy Middle: Assessing Students' Inquiry Skills Through Doing and Writing
}

\author{
Haiying Li ${ }^{(\bowtie)}$, Janice Gobert, and Rachel Dickler \\ Graduate School of Education, Rutgers University, \\ New Brunswick, NJ 08904, USA \\ \{Haiying. li, Janice. Gobert, \\ Rachel.Dickler\}@gse.rutgers.edu
}

\section{Erratum to: \\ Chapter "Dusting Off the Messy Middle: \\ Assessing Students' Inquiry Skills Through Doing \\ and Writing" in: E. André et al. (Eds.), Artificial Intelligence \\ in Education, LNAI 10331, \\ https://doi.org/10.1007/978-3-319-61425-0_15}

The original version of this chapter contained an error in the third author's name. The spelling of Rachel Dickler's name was incorrect in the header of the paper. The author name has been corrected. 